\title{
CORRECTION
}

\section{Correction to: Treatment Strategies for Dravet Syndrome}

\author{
Kelly G. Knupp ${ }^{1}$ - Elaine C. Wirrell ${ }^{2}$
}

Published online: 20 July 2018

(c) Springer Nature Switzerland AG 2018

\section{Correction to: CNS Drugs (2018) 32 (4):335-350 https://doi.org/10.1007/s40263-018-0511-y}

Page 335, Abstract: The sentence that read:

Benefit has also been noted with topiramate, levetiracetam, the ketogenic diet and vagal nerve stimulation.

Should read:

Benefit has also been noted with stiripentol, topiramate, levetiracetam, the ketogenic diet and vagal nerve stimulation.

The original article can be found online at https://doi.org/10.1007/ s40263-018-0511-y.

Elaine C. Wirrell

wirrell.elaine@mayo.edu

1 Departments of Pediatrics and Neurology, School of Medicine, University of Colorado Anschutz Medical Campus, Aurora, CO, USA

2 Divisions of Child and Adolescent Neurology and Epilepsy, Department of Neurology, Mayo Clinic, 200 First St SW, Rochester, MN 55902, USA 